\title{
FUSION SOLUTION TO DISPOSE OF SPENT NUCLEAR FUEL, TRANSURANIC ELEMENTS, AND HIGHLY ENRICHED URANIUM
}

\author{
Yousry Gohar \\ Fusion Power Program, Technology Development Division \\ Argonne National Laboratory, 9700 South Cass Avenue \\ Argonne, IL 60439, USA \\ Telephone: 630 252-4816, Fax: 630 252-5287, E-mail: gohar@anl.gov
}

\begin{abstract}
The disposal of the nuclear spent fuel, the transuranic elements, and the highly enriched uranium represents a major problem under investigation by the international scientific community to identify the most promising solutions. The investigation of this paper focused on achieving the top rated solution for the problem, the elimination goal, which requires complete elimination for the transuranic elements or the highly enriched uranium, and the long-lived fission products. To achieve this goal, fusion blankets with liquid carrier, molten salts or liquid metal eutectics, for the transuranic elements and the uranium isotopes are utilized. The generated energy from the fusion blankets is used to provide revenue for the system. The long-lived fission products are fabricated into fission product targets for transmutation utilizing the neutron leakage from the fusion blankets. This paper investigated the fusion blanket designs for small fusion devices and the system requirements for such application. The results show that $334 \mathrm{MW}$ of fusion power from D-T plasma for thirty years with an availability factor of 0.75 can dispose of the 70,000 tons of the US inventory of spent nuclear fuel generated up to the year 2015. In addition, this fusion solution eliminates the need for a geological repository site, which is a major advantage. Meanwhile, such utilization of the fusion power will provide an excellent opportunity to develop fusion energy for the future.
\end{abstract}

\section{Introduction}

Fusion can provide a complete and attractive solution for the national and the international disposition problems of the spent nuclear fuel, the transuranic elements, and the highly enriched uranium. In addition, the fusion technical requirements for these functions are very modest, and the current nuclear technologies are adequate. This will provide an excellent opportunity to develop fusion as an energy source for the future while providing a near term solution for these problems. For example, in the United States, the inventory of the spent nuclear fuel will reach 70,000 tons by the year of 2015. In this spent nuclear fuel, a small fraction of the uranium fuel is utilized for energy production, producing fission products and transuranic elements. This inventory of spent nuclear fuel consists of about 67,000 tons of uranium, 600 tons of transuranic elements, and 2400 tons of fission products. Most of the fission products have relatively short half-lives, tens of years. To dispose the spent nuclear fuel, uranium, fission products, long lived fission products $\left(\mathrm{Tc}^{99}\right.$, $\mathrm{I}^{129}$, etc.), and transuranic elements are separated. Uranium can be recycled in fresh fuel or disposed as low-level radioactive waste (Class-C waste). The fission products will be processed for disposal in a temporary repository to decay. The long-lived fission products will be fabricated into fission product targets for transmutation utilizing the neutron leakage from the fusion blanket to the shields. The transuranic elements will be fissioned in fusion blankets and the generated energy is used to generate revenue for the system. Also, fusion option can be used to dispose of the current 


\section{DISCLAIMER}

This report was prepared as an account of work sponsored by an agency of the United States Government. Neither the United States Government nor any agency thereof, nor any of their employees, make any warranty, express or implied, or assumes any legal liability or responsibility for the accuracy, completeness, or usefulness of any information, apparatus, product, or process disclosed, or represents that its use would not infringe privately owned rights. Reference herein to any specific commercial product, process, or service by trade name, trademark, manufacturer, or otherwise does not necessarily constitute or imply its endorsement, recommendation, or favoring by the United States Government or any agency thereof. The views and opinions of authors expressed herein do not necessarily state or reflect those of the United States Government ois any agency thereof. 


\section{DISCLAIMER}

Portions of this document may be illegible in electronic image products. Images are produced from the best available original document. 
inventory of the transuranic elements and the highly enriched uranium by utilizing its energy content and transmuting its long lived fission products, which represents a complete and attractive solution for this problem.

The main objectives of this investigation are to introduce the fusion solution and to size the required fusion system for solving the US spent fuel problem as an example for such application. In this solution the transuranic elements and the long-lived fission products are eliminated, the radioactive waste volume is minimized, the generated energy from the transuranic elements is used for generating revenue for the system, and the need for a geological repository is eliminated. D-T fusion neutrons are used for achieving these goals with minimum fusion power.

\section{Molten Salt Blanket Concept}

The self-cooled molten salt blanket concept is considered as an example to quantify the performance of the fusion solution and the results are used to size the required fusion system to achieve the elimination goal for solving the US spent fuel problem. Flibe molten salt $\left(\mathrm{Li}_{2} \mathrm{BeF}_{4}\right)$ was developed and used for the Molten Salt Breeder Reactor (MSBR) [1 and 2]. Molten salt technologies were developed for MSBR in the 1960 's, for the fuel cycle of the fast breeder program in the 1990's, and for decommissioning the molten fuel salt of the MSBR in the 1990's. Flibe characterization included the physical properties, the corrosion issue, the chemical processing, and the solubility of the fuel compounds and the fission products in the salt $[2$ and 3]. $\mathrm{UF}_{4}, \mathrm{ThF}_{4}$, and $\mathrm{PuF}_{3}$ are the fuel compounds selected for the MSBR. For the disposal of transuranic elements, $\mathrm{PuF}_{3}$ is the material of interest. $\mathrm{PuF}_{3}$ is a solid with a density of $9.32 \mathrm{~g} / \mathrm{cm}^{3}$ and it has a melting point of $1425^{\circ} \mathrm{C}$. The solubility of $\mathrm{PuF}_{3}$ in Flibe was measured [3] for composition ranging in $\mathrm{BeF}_{2}$ from 28.7 to 48.3 mole in the temperature range of 450 to $650^{\circ} \mathrm{C}$.

A poloidal blanket configuration is considered where the inlet and the outlet manifolds are located at the top section of the reactor. The salt coolant is first introduced to the front section of the blanket to remove the surface heat flux from first wall. Then, the flow direction changes at the bottom of the reactor to leave the blanket module at the top. This flow pattern simplifies the reactor manifold system.

At the start, it is foreseen to operate the blanket without transuranic elements to confirm and calibrate the operation of the different systems. This mode of operation reduces the shielding capability of the blanket due to the absence of the neutron absorbers, the transuranic elements. Therefore, the blanket radial thickness was first defined with pure Flibe as a function of the blanket radial thickness, where the Flibe zone thickness was varied from 0.2 to $0.6 \mathrm{~m}$. The results show that a $0.5-\mathrm{m}$ Flibe zone thickness is required to reduce the energy deposition in the shield to $\sim 4 \%$ of the total energy deposition. At this blanket thickness, all the shielding performance parameters are quite satisfactory.

The second step defined the blanket performance with $\mathrm{PuF}_{3}$ dissolved in the Flibe. The $\mathrm{PuF}_{3}$ weight fraction varied parametrically in the range of 0.0025 to 0.0275 , which is consistent with the experimental results. The results show that the blanket performance parameters change monotonically in this range. The first two blankets of Table 1 give the main blanket performance parameters for the extreme values of the range. As the $\mathrm{PuF}_{3}$ concentration in the Flibe salt increases, all the blanket performance parameters improve. At the highest $\mathrm{PuF}_{3}$ concentration, the plutonium transmutation rate is $4.4 \mathrm{~kg} / \mathrm{MW} . \mathrm{y}$ of fusion power. The corresponding tritium-breeding ratio and the blanket energy multiplication factor are 2.2 and 15.3 , respectively. This high tritium-breeding ratio indicates that the lithium- 6 concentration can be reduced to increase the plutonium transmutation rate and to reduce the tritium-breeding ratio.

The blanket performance analyzed parametrically as function of the lithium- 6 concentration in the range of 2.5 to 7.5 (natural) \% with constant $\mathrm{PuF}_{3}$ concentration. As the lithium- 6 concentration decreases, the blanket performance parameters improve monotonically. The plutonium transmutation rate changes from 3.4 to 48 $\mathrm{kg} / \mathrm{MW} . \mathrm{y}$ as the lithium- 6 concentration varies 
from $7.5 \%$ (natural lithium) to $2.5 \%$. However, the local tritium-breeding ratio is very high, it has a value of 10.8 for the $2.5 \%$ lithium- 6 concentration as show in Table 1. This suggests that the $2.5 \%$ lithium -6 concentration is high and it can be reduced further allowing more neutrons for transmuting plutonium. Also, the $\mathrm{PuF}_{3}$ concentration can be reduced for the same transmutation rate, which enhances the safety characteristics of the system. The blanket energy multiplication factor reaches 160 , which provides good revenue to recover the transmutation cost. Then the blanket configuration analyzed with $100 \%$ lithium-7 and the $\mathrm{PuF}_{3}$ weight fraction in the flibe iterated to get $K_{\text {eff }}$ of 0.98 for sub-critical operation. Table 1 gives the performance parameters for such blanket configuration. The plutonium transmutation rate is $72.6 \mathrm{~kg} / \mathrm{MW}$.y of fusion power, which is quite satisfactory. The blanket energy multiplication and the energy fraction in the shield are 242.6 and 0.018 . However, the tritium-breeding ratio of this blanket is 0.488 , which is not adequate for tritium selfsufficiency. Therefore, a very small concentration of lithium- 6 needs to be used for a small operating period to accumulate enough tritium for selfsufficiency. Therefore, a lithium- 6 concentration of $0.25 \%$ is utilized and the $\mathrm{PuF}_{3}$ concentration adjusted to get $\mathrm{K}_{\text {eff }}$ of 0.98 . The resulting performance parameters are given in Table 1, which are quite satisfactory. The analyses show that lithium-6 act as a burnable absorber. As its concentration increases, the required concentration of $\mathrm{PuF}_{3}$ is increased to maintain the same $\mathrm{K}_{\mathrm{eff}}$ value. The lithium- 6 concentration decreases as the reactor operates as well as the $\mathrm{PuF}_{3}$ concentration. The tritium-breeding ratio with low lithium -6 concentration is very high, which allows the reactor to operate without lithium- 6 for extended periods. Since the accumulated tritium will be adequate to insure tritium self-sufficiency. It is possible to use a lower value and consequently a lower $\mathrm{PuF}_{3}$ concentration. A system analysis is required to define the optimum lithium- 6 and $\mathrm{PuF}_{3}$ concentrations taken into consideration economic, safety, and material issues.

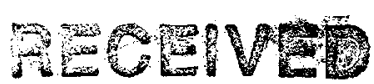

OCT 062090

\section{Fusion power requirements for disposing of the US inventory of the spent nuclear fuel}

The total amount of transuranic elements in the US inventory of the spent nuclear fuel will reach 600 tons by the year 2015. A molten salt fusion blanket with $\mathrm{k}_{\text {eff }}$ of 0.98 can transmute $\sim 79.7 \mathrm{~kg}$ of transuranic elements per MW.y of fusion power as shown in Table 1. To transmute the total US inventory, a fusion fluence of $7528 \mathrm{MW} . \mathrm{y}$ is required. A 334-MW of fusion power can provide such fluence over 30 years assuming an availability factor of 0.75 . However, the thermal output from the blanket is too large for a single unit. For example, five fusion reactors with 33.5 MW of fusion power each can perform such function. The thermal power from each reactor is $7258 \mathrm{MW}$, which generates a gross electrical power of $\sim 2468 \mathrm{MW}$. Such fusion reactors can be constructed based on the current technology with driven plasma, which provides near term solution for the spent nuclear fuel disposition and an opportunity to develop fusion energy.

In addition, the analysis of the molten salt blanket shows that the transmutation rate and the blanket thermal output can be adjusted over a wide range, which provides a large flexibility to choose the reactor parameters including the fusion power level. Such flexibility is important for the longterm development of fusion reactors. For example, a larger fusion power can be used if it is required for the development of the plasma physics or the reactor technology where the concentration of the lithium- 6 and the transuranic elements can be adjusted to achieve the target values of thermal output, transmutation rate, and tritium breeding ratio. Also, the number of the long-lived fission product targets inserted in the fusion reactor for transmutation can be adjusted to regulate the thermal output as required.

\section{Conclusions}

Fusion blankets with liquid carrier for the transuranic elements and the uranium isotopes achieve the elimination goal, which is the top rated solution for the disposition of the spent nuclear 
fuel, the transuranic elements, and the highly enriched uranium. This type of blankets reaches a transmutation rate up to $80 \mathrm{~kg} / \mathrm{MW}$.y of fusion power. The energy from the transmutation process is utilized to produce revenue for the system. For the disposition of the spent nuclear fuel, the fusion solution eliminates the need for a geological repository, which is a major advantage. Flibe molten salt and lithium-lead eutectic are identified as the most promising liquids for this application where both materials are under development for future fusion blanket concepts.

Meanwhile, this application will provide an excellent opportunity to develop the fusion energy for the future by building small fusion devices. A 334-MW of fusion power for thirty years with an availability factor of 0.75 can transmute all the transuranic elements and the long-lived fission products in the 70,000 tons of the US inventory of spent nuclear fuel generated up to the year 2015 . These devices will have an operating flexibility, which can be achieved by adjusting the blanket parameters to maintain an acceptable thermal output for generating revenue. The small fusion power and the operating flexibility will provide a mechanism to develop the fusion energy for the future.

Further analyses and studies are needed to develop such system considering previous work including non-fusion options. Definition of the different system components, identification of the technical issues that require resolution, schedule and plan to resolve these issues, total cost estimate of the system, and comparison with the other options under consideration need to be included in these studies. Blanket concept development requires special attention since its performance has a major impact on the whole system. These developments can utilize the existing technologies to minimize the R\&D cost and the schedule to complete the disposition process.

The submitted manuscript has been created by the University of Chicago as Operator of Argonne National Laboratory ("Argonne") under contract No. W-31-109-ENG-38 with the U.S. Department of Energy. The U.S. Government retains for itself, and others acting on its behalf, a paid-up, nonexclusive, irrevocable worldwide license in said article to reproduce, prepare derivative works, distribute copies to the public, and perform publicly and display publicly, by or on behalf of the Government.

\section{References}

1. J. R. McWherter, "Molten Salt Breeder Experiment Design Bases," Oak Ridge National Laboratory Report, ORNL-TM-3177, November 1970.

2. R. E. Thoma, "Chemical Aspects of MSRE Operation," Oak Ridge National Laboratory Report, ORNL-4658, December 1971.

3. R. E. Thoma, "Chemical Feasibility of Fueling Molten Salt Reactors with $\mathrm{PuF}_{3}$," Oak Ridge National Laboratory Report, ORNL-TM-2256, October 1968.

Table 1. Flibe blanket performance parameters with different plutonium weight fractions and lithium-6 enrichments.

\begin{tabular}{|l|c|c|c|c|c|c|}
\hline PuF $_{3}$ weight fraction & 0.0025 & 0.0275 & 0.024 & 0.024 & 0.00051 & 0.0056 \\
Lithium-6 enrichment & Natural & Natural & 2.5 & Natural & 0.0 & 0.25 \\
\hline Blanket energy multiplication factor & 1.765 & 15.052 & 157.2 & 1.98 & 242.6 & 264.0 \\
Total energy multiplication factor & 1.819 & 15.262 & 160.0 & 12.15 & 251.5 & 270.9 \\
Local tritium breeding ratio & 1.214 & 2.180 & 9.469 & 1.956 & 0.488 & 10.740 \\
Shield energy fraction & 0.030 & 0.014 & 0.018 & 0.014 & 0.0352 & 0.0252 \\
Fission reactions per D-T neutron & 0.049 & 0.986 & 10.78 & 0.770 & 16.301 & 17.902 \\
Pu transmutation rate, kg/MW.y & 0.219 & 4.390 & 47.98 & 3.428 & 72.560 & 79.689 \\
$\mathrm{~K}_{\text {eff }}$ & 0.125 & 0.741 & 0.969 & 0.691 & 0.979 & 0.981 \\
\hline
\end{tabular}

